\title{
TOOLS FOR HANDLING HUMAN AND \\ ORGANIZATIONAL PROBLEMS OF \\ COMPUTER-BASED INFORMATION SYSTEMS
}

\author{
FRANK KOLF \\ HANS-JÜRGEN OPPELLAND \\ DIETRICH SEIBT \\ NORBERT SZYPERSKI
}

\author{
Betriebswirtschaftliches Institut für \\ Organisation und Automation \\ Universität zu Köln \\ D-5000 köln-Lindenthal
}

\section{A B S T R A C T}

The last decade has confronted system designers with the problem that they have to consider the requirements and restrictions of human and organizational context in system development processes. There are lots of tools for supporting the technical design activities but until now project management is lacking effective and efficient tools for handing the human and organizational problems in system design. The paper describes some tools which were developed in the research project PORGI (Planning model for the Organizational Implementation) and are currently tested in CBIS-projects in two German companies. 
1. Organizational implementation of computer-based information systems $(=$ CBIS $)$

Literature on the development of CBIS as well as activities of system analysts and system designers have been and still are dominated by many attempts to solve technological questions (concerning computers, programs, data bases, methods, models etc.). There exists a continuously growing number of tools to support these activities (e.g. techniques for program design, interactive programing support systems, documentations methods and systems etc.).

Roughly since 1970 some large organizations (companies etc.) try to achieve computer-based management information systems especialIy to support management planning and control processes. These systems not seldom perform multiple functions and/or serve users in multiple areas of the organization. They provide users with access to data and analytical capabilities which previously were not available to them. Trying to develop such systems a special kind of "implementation" problems originated, which system designers used to attribute to the fact, that "users" have only insufficient technological knowledge and therefore are not able to make optimal use of CBIS.

More and more it became clear that introduction and usage of CBIS in existing organizational environments was confronted with large difficulties comparable to those which originate with implantations of artificial organs into the human body. In many cases potential user departments put the new systems under a boycott. As a consequence diligent system analysts invented an additional phase in the development process, the core of which was "user-training". In parallel they were active to find out necessary modifications of user behavior and of the organizational structures and tried to convince management to perform those modifications. But then new difficulties arouse in form of feed-back-effects to the technological solutions designed in earlier phases of the development process. In many cases "trained users" were no longer satisfied with the system, they themselves had defined before as they had experienced learning processes. They changed their demands and needs. New incompatibilities between the future system and its environment arouse. 
The date of system-delivery to the user had to be postponed, planned budgets could not be held, this being only few out of a large number of frustrations which hit users and system analysts participating in these situations.

Some consequences hat to be drawn from these experiences. The traditional understanding of "organizational implementation" and of its position in the process of system development had to be modified:

- objects of system development are not only the technological components, but simultaneously and equally the organizational and personal components of an information system (as a sociotechnical system)

- the core of system development is to produce a fit between technological, organizational and personal system components. System development can only be successful, if activities to produce this fit, to integrate system components, start with the beginning of the design phases. Organizational implementation is understood here as this central process of integrating, mutually adjusting system components.

From another point of view: system development is a special form of "planned change or organizational innovation", a term which is influenced by social science thinking.

This approach is not very new. Many authors have already mentioned this point. There is a lot of publications especially on empirical studies dealing with personal and organizational aspects of system development processes:

a) Several papers stress the enormous importance of factors like - user participation 1),

- top management support ${ }^{2)}$,

- overcoming user resistance to change ${ }^{3)}$.

Authors of these papers always have only relatively small samples at hand on which they base their statements. Most of their conse-

1) e.g. Little $=$ Models $=$ Carter/Gibson/Rademacher = Critical Factors =

2) e.g. Radnor/Rubenstein/Bean = Integration $=$; Radnor/Rubenstein/ Tansik = Implementation =

3) Huysmans $=$ Joint Consideration = 
quences is not discussed.

b) Some studies concentrate on "impacts": impacts of CBIS on individuals or small groups"), impacts of certain technological components or special forms of CBIS on decision behavior ${ }^{2}$, or impacts of CBIS on organization structure ${ }^{3)}$. Most of these investigations represent mono-causal explanations, i.e. impacts studied are attributed solely or mainly to the introduction of CBIS or traced back exclusively to changes of technological system-components.

c) In a third kind of studies the relations between certain factors or groups of factors and success of CBIS-implementation are analysed ${ }^{4)}$. The problem here is the variety of factors investigated. Studies are concentrating on different groups of factors, on different types of information systems and different organizational and personal settings of $\mathrm{CBIS}^{5}$. In many cases results of these studies are contradictory. You find a large number of single statements without any help how to coordinate them.

d) Many studies have a retrospective orientation. Relations between factors are analysed ex-post. Empirical data are mostly collected after system development has been finished. There are only few statements on the process of system development. This leads to the fact, that system people don't find much information in these studies which could help them directly with their daily work.

We think that implementation research in the field of CBIS as a special form of technological research should produce tools to improve the effectiveness of system development activities. Besides that it should generate empirically founded statements how to use these tools in an individual context. It should stress important attributes of organizational implementation in different situations.

1) Dyckman = Additudinal Study $=$; Shaw = Group Dynamics =; Ladd $=$ Group's Reaction $=$; Schultz/Slevin = Organizational Validity $=$; Sorensen $/$ Zand = Improving =; Vertinsky/Barth/ Mitchell = Social Change $=$

2) Hedberg $=$ Man-Computer $=$; Chervany/Dickson = Information over Load $=$

3) Whisler $=$ Impact of Computer $=;$ Lucas $=$ Performance $=$; Bean $/$ Neal/ Radnor $/$ Tansik = Correlates $=$

4) Ginzberg = Implementation = gives a very comprehensive survey on such factor-studies;

5) Harvey $=$ Factors $=$; Powers $/$ Dickson = MIS =; Lucas = Systems =; Bean/Neal $/$ Radnor $/$ Tansik = Correlates = 
The management of system development is context-dependent. General rules and general statements must be substituted by specialized combinations of methods and techniques which take account of special conditions of implementation cases.

These and other objectives are pursued in research project PORGI, which is sponsored by the German Federal Ministry for Research and Technology. Within this project we try to generate instruments for CBIS development

- which help to measure the fit (or mis-fit) respectively the degree of integration between technological, organizational and personal system components (= specialized methods for analysis/diagnosis)

- which help to produce a better fit between system components by concentrating on these fit problems.

A multi-stage research and design process is provided for this project:

\section{Stage 1}

Design of a first global version of a descriptional framework, which contains all important factors by which O.I.-situations may be characterized.

\section{Stage 2}

Empirical research: interviews with 50 experts in the field of information systems ( 22 cases). One purpose of these interviews was to examine the descriptional framework and to detail it in such a way that it is able to map all factors which are named by the experts as being important factors in their individual O.I.cases. A second purpose was to generate context-dependent hypotheses about how implementation processes have been performed in different organizational settings, which tools have been or not been used to produce fit between system components.

\section{Stage 3}

Classification of typical implementation situations, problem and process profiles of these situations based on the expert interviews.

\section{Stage 4}

Development of techniques and methods to measure implementation situations, to diagnose problems and to derive specialized recommendations to overcome these problems. 
Stage 4 a (actual state of project PORGI)

Application of these techniques and methods in a certain number of cases in order to examine and continously improve them in the pracm tice of system development. At the moment the research team is participating in CBIS-projects in two German companies. The same purpose of examination and methodological improvement is pursued in a working group consisting of several German CBIs-experts belonging to different institutions and the members of the PoRGI-team.

\section{Stage 5}

Collection and comprehension of all tools in a "handbook for organizational implementation of CBIS", which will support practitioners in system development and will be the basis for training courses performed to disseminate this kind of know-how.

The next chapter gives an overview about all tools prepared in project PORGI. These tools are then portrayed in some details during chapters $3-7$. Chapter 8 shows the procedural interactions between these tools when used in system development. Chapter 9 points to some important implications and limitations of the approach. The appendix presents some examples of PORGI-tools. 
2. Synopsis of the PORGI-Tools

The concept of the PORGI-Tools for the support of handing the human and organizational problems in the development of CBIS consists of five elements : (See figure 1)

- Descriptional Framework (DF) for implementational situations

- Procedural Scheme (PROC) as an example for the sequence of design activities which has to be adapted to the design phases in a specific context. The design activities are associated with relevant organizational implementation (OI) activities and tools for handling these activities.

- A Pool of Methods (METH) for the support of OI-activities, especially those instruments, tolls and methods for analyzing and diagnosing implementational situations which are developed by the PORGI-team.

- A POol of typical implementational problems (PROB), which have occured in typical situations.

- A Pool of Design Concepts (CON) consisting of procedure-oriented and system-oriented design-recommendations.

The following pages will give a closer look at some of these five components.

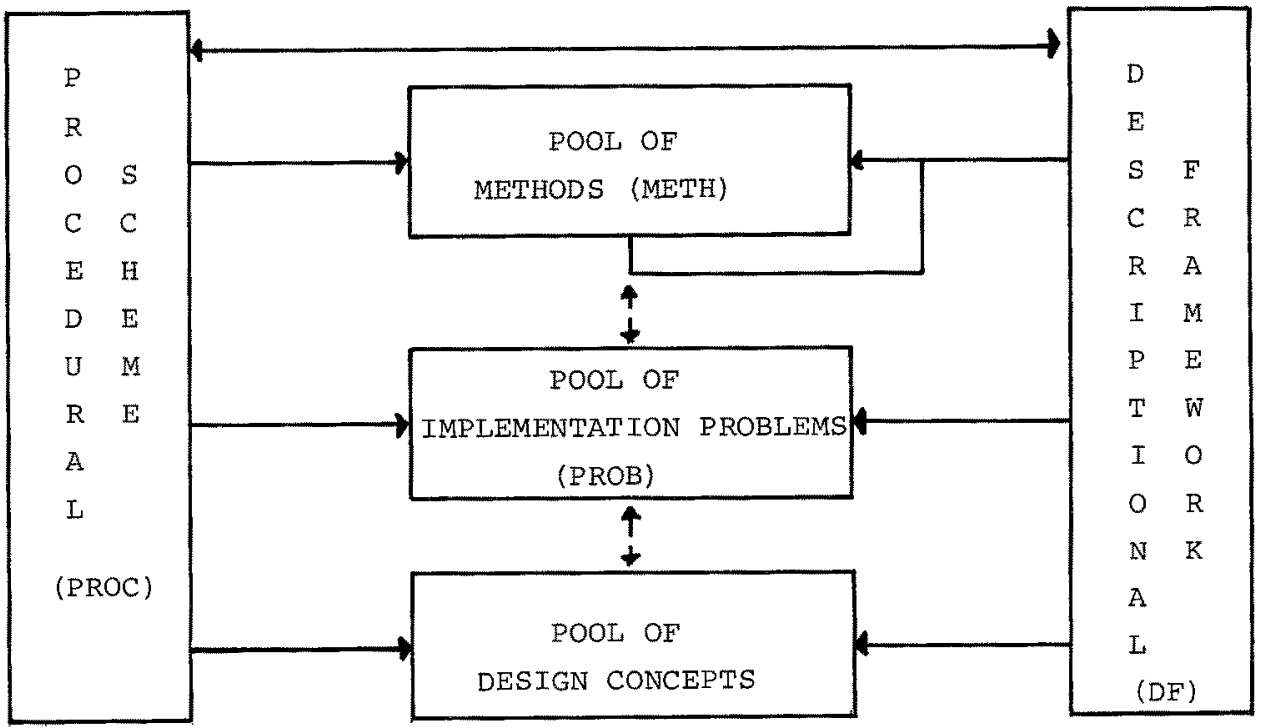

Fig. 1 : Synopsis of the PORGI-Tools 
3. The Descriptional Framework (DF)

We have already mentioned that all components have to be oriented at the categories of a common descriptional framework.

That framework serves as a common terminological basis and not as an explanatory model. The DF contains all those principal elements which constitute specific implementational situations. That does not mean that all elements have to occur in a specific situation. According to the underlying implementation philosophy we have to differentiate two areas of analysis :

- analysis of the fit between the system components "man, organizational structure, information technology and the task" to be supported; ${ }^{1)} \quad$ (System Fit)

- analysis of the design process (the project organization, project management etc.) (Process Fit)

The principal categories of the DF are grouped into four modules ${ }^{2}$ )

- Personal System

- Task

- Information Technology

- Organization structure

These principal categories are abstracts from concrete situations. In a specific context, design situation etc. these categories have to be specified in terms of that individual situation. For instance we don't speak in global terms of "the user" but we differentiate functional criteria which enable us within a specific situation to describe those people which have to be considered as "users", e.g. those who have to deliver inputs to the system, and will receive ouputs from the system, their educational background, their job record, needs and so on. The following pages give an idea of that principle by showing a part of the module "Organization structure".

1) These components are oriented at Leavitt's categories Man, Structure, Technology and Task. See Leavitt $=$ Change $=$

2) For the structure of the DF see Szyperski/Kolf/Claus/oppelland/ = Implementation = and especially Kolf/Claus/oppelland

$=$ Beschreibungsmodell = 

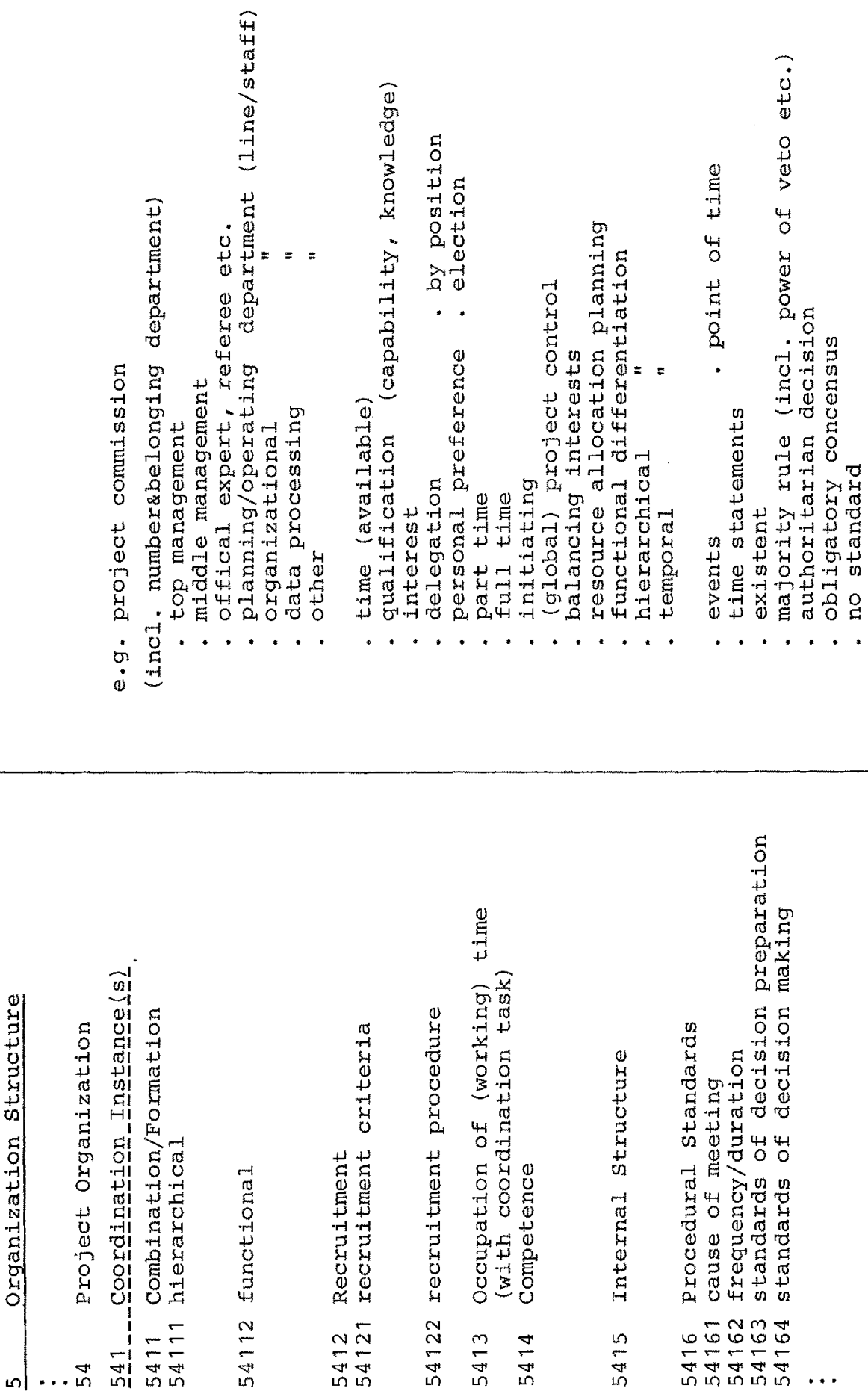
4. The Procedural Scheme (PROC)

The Procedural Scheme consists of a sequence of well known design activities. Associated with the different design activities are implementational aspects and specific tools to support the analysis of these aspects. Iike the other PORGI-tools the procedural scheme also has to be adapted to a specific situation, e.g. the sequence of the design activities may be different in different situations, or the number of separate activity blocks may vary depending on the project's complexity, budget, involved manpower etc. The conception of that procedural scheme has been guided by the following principles :

- Based on our definition of the organizational implementation as a process of securing the well-tuned design of the system components Man, Task, Structure and Information Technology there have to be planned specific activities which enable us to verify that tuning from the start-up-phase of the project.

- The design activities have to be supplemented by specific analytical steps. By performing repeated status analyses of all the system components we get information about the design status of the different components and FIT of these components. The evaluation of actual and planned status indicates specific (potential) problem areas early in the design process which have to be counteracted.

- Those who are concerned with system design and for system usage have to be involved in the degree of their individual concern. Therefore we have to plan activities which ensure that the organization of the design process besomes a design variable too.

The following abstract from the PORGI-Procedural-Scheme shows the realization of these principles. The nature and function of the analytical tools mentioned in the last column will be explained in chapter 5 . 

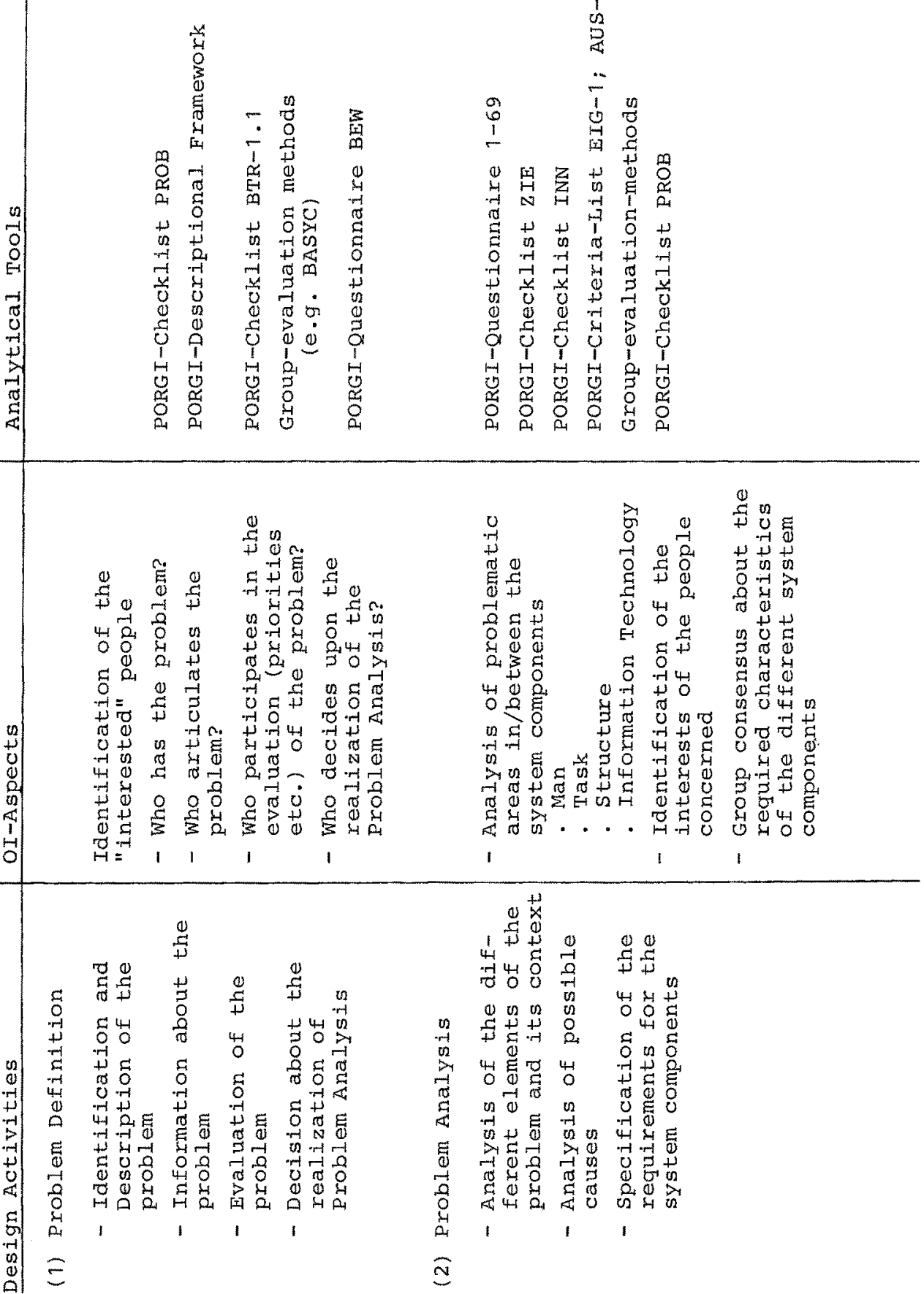


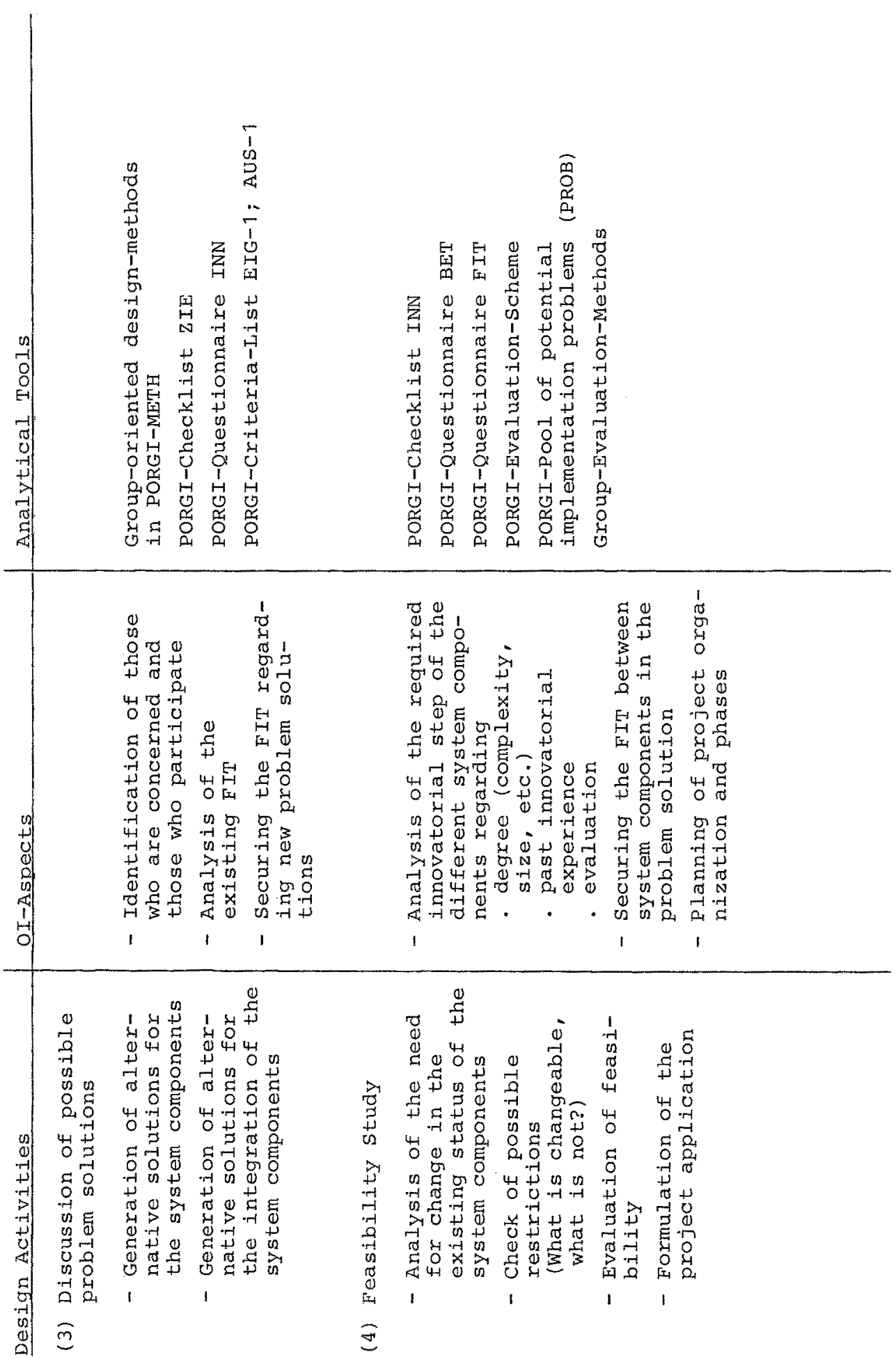




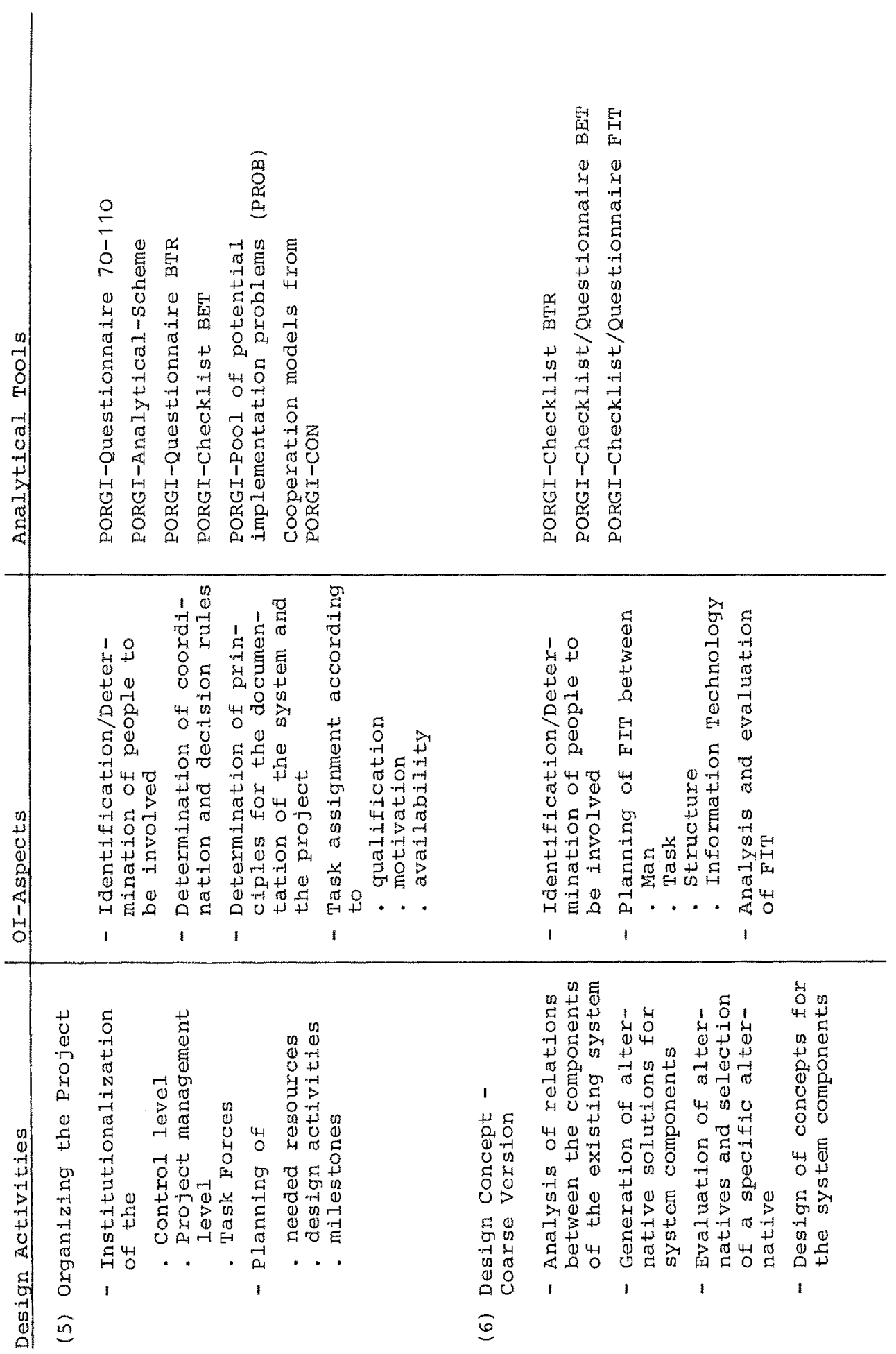




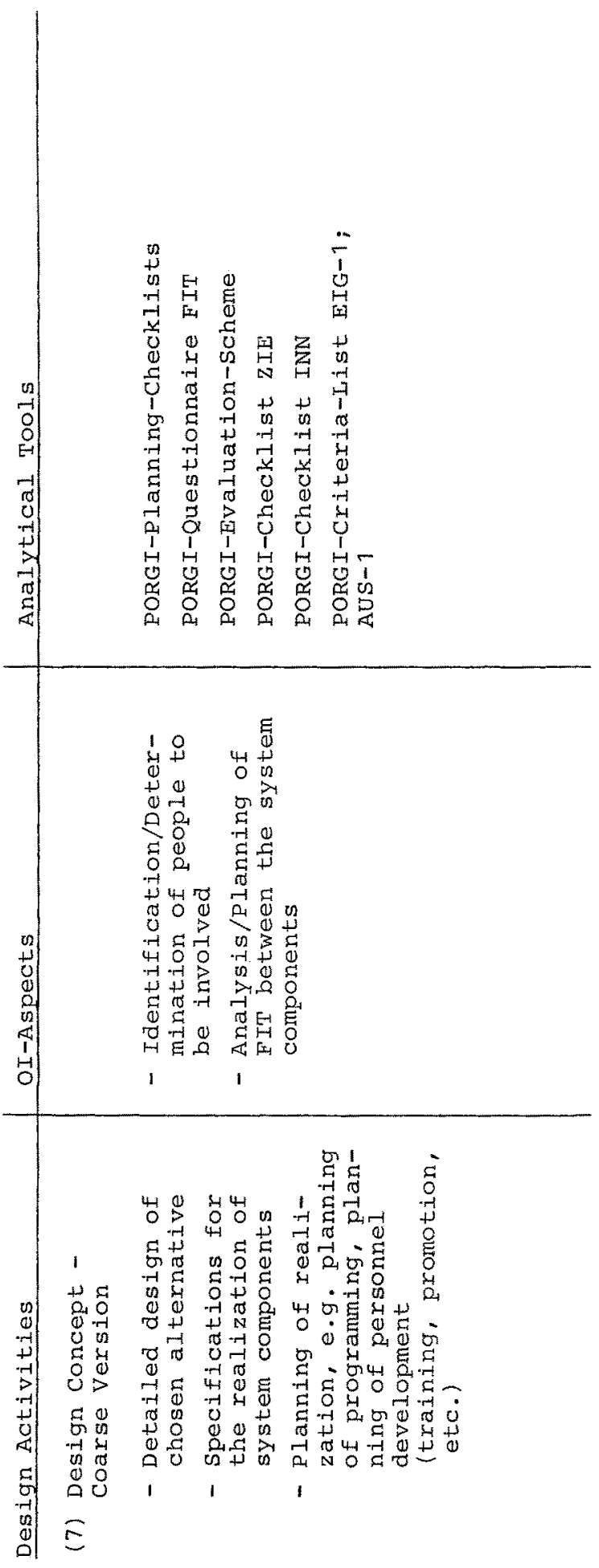


5. Pool of Methods for System Development

\subsection{Classification of methods}

Most development methods have in common that they apply systematic procedures for solving problems of (information) system development but differ in the degree of specialization, applicability and design efforts.

They are methods for

- collection,

- description,

- analysis and diagnosis,

- forecasting,

- design and model,

- planning and control,

the characteristics, structure, state, behavior, performance etc. of models, systems, elements and design-processes in conception and reality.

Specialized methods (or special purpose methods) are those, which are mainly applicable in specific areas and to selected objects. We think it is helpful to differentiate two groups of specialized methods :

(1) Specialized methods for technical system development :

- assume well defined problems; intend to solve the problem efficiently from an engineering point of view,

- do not explicitly consider the social and organizational environment.

(2) Specialized methods for socio-technical system development :

- concentrate on "wicked" problems of system development and consider social and organizational environment,

- focus on integrative aspects of system development,

- conceive design and implementation as a necessarily social interaction process,

- assume definition of system objectives as depending on social learning processes and therefore changing over time.

In addition we can find different types of methods which focus on different developmental aspects, i.e. regarding the group of 
(1) specialized methods for technical system development, especially for the
(a) design of system components
(b) integration of system components
(c) management of the system development process
and regarding the group of

(2) specialized methods for socio-technical system development those for

(a) system design and implementation

(b) system development process support.

In order to improve a better mutual understanding here we add a summary of our method classification with some examples for their explanation.

A. General (basic) methods

1) description methods

- graphical description (network-structures, structograms, flow charts, etc.)

- matrix presentation

- profile presentation

- verbal presentation

2) collection methods

- observation

- interview

- questionnaire

- document analysis

3) analysis/diagnosis methods

- regression analysis

- correlation analysis

- ABC-analysis

- utility analysis (Nutzwertanalyse)

4) modelling/design methods

- simulation

- optimization

- stepwise refinement

- morphological methods 
B. Specialized methods for system development

1) methods for technical system development

a) methods for design of system components

- structured programing

- Jackson diagram

etc.

b) methods for integration of system components

- Kölner Integrationsmodell (KIM)

- AEG-Telefunken-ModelI

etc.

c) methods for the support of administrative aspects

of system development processes

- PAC II

- IFA-PASS

- ORGWARE

2) methods for socio-technical system development

a) methods for system design and implementation

- ETHIC (Munford)

- BASYC (Hawgood, Land, Mumford)

- MIRA/SPIRA (Taggart, Tharp)

- PORGI-System FIT

b) methods for the support of socio-technical aspects of development processes

- PORGI-process FIT

Regarding to the PORGI approach there is a special need for processoriented methods, which enable all those who are presumed users of the system in managing the social interactions in developmental. processes.

As a first step PORGI intends to attain the development of appropriate instruments to achieve this socio-technical design support. The following chapter (5.2) presents some of these instruments.

5.2 Instruments, Tools and Methods for Analyzing and Diagnosing Implementational situations

The above mentioned Procedural Scheme (PROC) for all design activities points to such aspects, which have to be considered in the 
view of what we call organizational Implementation (see chapter 4, the middle column). With these different aspects are associated instruments, tools and methods for their analysis and diagnosis, which will be combined to the planned Implementation Handbook (IHB). Problem-oriented questionnaires, checklists, lists of criteria etc. support the diagnosis and analysis of constellations of variables, which are relevant to organizational implementation activities in this specific situation.

As an example for problem-oriented questionnaires we offer those named "SITUATIONAL DIAGNOSIS" (BET, BTR) and "METE" (ORG-INT), wich are suitable for the organizational implementation (O.I.) activities "Planning of process-EIT and system-FIT" according to the system development step (6) Design-Concept-Coarse-Version (see the special marks in the above presented procedural scheme and the explanation in chapter 5 and the appendix).

In the appendix you will find parts of these PORGI-questionnaires, which intend to enable those, who are concerned with the system development, to analyze the fit of the outlined system design concept and the perceived design and implementation process by themselves. These questionnaires are developed under certain assumptions of cause/effect-relations, which are based on empirical data of the PORGI-expert-interviews and design experiences of the PORGIteam-members.

As our empirical experiences indicate a special effect of questionnaire application can be seen in a "participation-by-answeringeffect", which influences the development process and therefore its success positively. Beyond that the questionnaire offer the chance to include users' demands, evaluation and attitudes adequately in system design. 1)

As an example of a PORGI-checklist we present the checklist PROB for the system development step (2) Problem analysis. This checklist "PROBLEM DEFINITION (PROB)" intends to ensure the consideration of all relevant situative aspects for the definition of

1) See e.g. Mumford = Job Satisfaction =; and = Procedures =; Hawgood $=$ Evaluation $=;$ Hawgood/Land/Mumford = Comparison $=$ 
system and system development objectives and problems.

The following list gives additional examples for instruments, which are developed in PORGI and which are now in an on-going process of empirical test and refinement in practical development projects :

- Checklist for the identification of those members of the organization who are concerned with the development process and/or will be system users;

- Checklist and questionnaire for the definition of project and system objectives;

- Checklist and questionnaire for the identification of those who are concerned with changes through system development and the expected concequences of these changes for their responsibility, autonomy of decision-making, control and other working conditions;

- Questionnaire for identification of actual and required participation in system development activities;

- Questionnaire and checklist for identification and analysis of the required/planned innovatiorial step and its importance regarding the system components :

Task, Personal System, Information Technology and Organization Structure, e.g. task content, procedures, communication;

- Checklist and questionnaire for the evaluation of the FIT between the system components by those who are concerned.

Checklists and questionnaires are instruments, which can be handled by the project management or special implementors according to the different steps of system development. The questionnaires are addressed to those members of the organization who are concerned with system design, implementation and use. 
6. Pool of Implementation problems (PROB) for the contextual analysis and diagnosis

This pool consists of specific implementation problems which can be identified by a situational profile. These profiles describe those empirical situations in which that specific implementation problem has occured repeatediy, e.g. results or consequences of specific actions in the design process which deteriorate the intended implementation success. These problems lead to economically and/or socially insuffient results of the system design process, process of system usage. Descriptions of these implementation problems use the categories of the descriptional framework and are based on those problems which have been identified in our expert interviews to be typical for specific situations.

Additionally it contains theoretically or empirically based implementation problems found in literature, case studies and own design experiences of the members of the PORGI-team. Objective of the diagnosis is the comparsion of the characteristics of the individual situation and the situative profile of the implementation problems of PROB in order to identify possible problem areas in the actual situation. Follow-up activities focus on the analysis of possible causes for that problem and possible solutions (see the CON-pool in the next chapter). 
7. POOL of Design Concepts (CON)

The result of the contextual analysis and diagnosis is the knowledge of specific implementational problems (which probably deteriorate the intended implementation success) and possible causes for these problems. Based on this result the PORGI-Design-Concepts support problem solution by helping to select appropriated implementational actions - appropriate for avoiding expected problems or reducing their possible consequences. But the design concepts should also be helpful to handle unexpected problems or reduce their consequences.

The choice of appropriated implementational actions is supported by offering

- general design principles and

- situative design proposals,

which can be seen as sufficiently tested and confirmed by the system development praxis. The description of these design concepts is also oriented at the categories of the descriptional framework, thus their situative applicability could be better evaluated in actual situations by the project manager, implementor or other people responsible for the system development.

The design concepts contain as possible implementational actions proposals to correct (or confirm) social and organizational behavior and its rules regarding the different aspects of

- organization and procedures of design and implementation processes, e.g.

. project planning, project organization

. participation of those who are concerned

. consideration of changes in the definition of project and/or systeri objectives

. improvement of implementational activities initiated by differences between actual

and plannea situations

- design of system components under consideration

of their fit to accepted

.. objective requirements

. subjective demanás and needs of those who are concerned with the system development and use. 
8. Procedural Interactions of the PORGI-Instruments

The interaction of the proceeding chapters has been to give an imagination of that kind of tools and instruments which have been developed by the PORGI-team and are currently under test in practical DP-Projects in industrial firms.

The following comments will show up briefly the procedural interactions of these instruments in the course of a design project. (See fig. 2)

The procedural scheme (PROC) works as a directory which tells us what next steps should be undertaken and what kind of implementational aspects should be considered. The details of such an oI-aspect (e.g. (5.1.1) Participation) are compiled in the Discriptional Framework (DF), in that example the elements of the group 1113 Individual evaluation of participation.

The Pool of Methods (METH) offers for the analysis of these OIaspects specific analytical tools, in the example the PORGI-Questionnaire BET (see the abstract in the appendix).

After having gathered facts about the specific situation by use of the PORGI-tools the problem-oriented analysis of that situation is being performed by searching the pool of implementation problems (PROB) . Objective of that search is to find out whether the situative profile just gathered is similar to one of those situative profiles in the problem pool in which specific implementation problems have repeatedly occured.

Then the pool of Design concepts (CON) is to be searched whether it contains a possible solution with a similar situative profile, that means a solution which has proven to be useful in similar situations. 


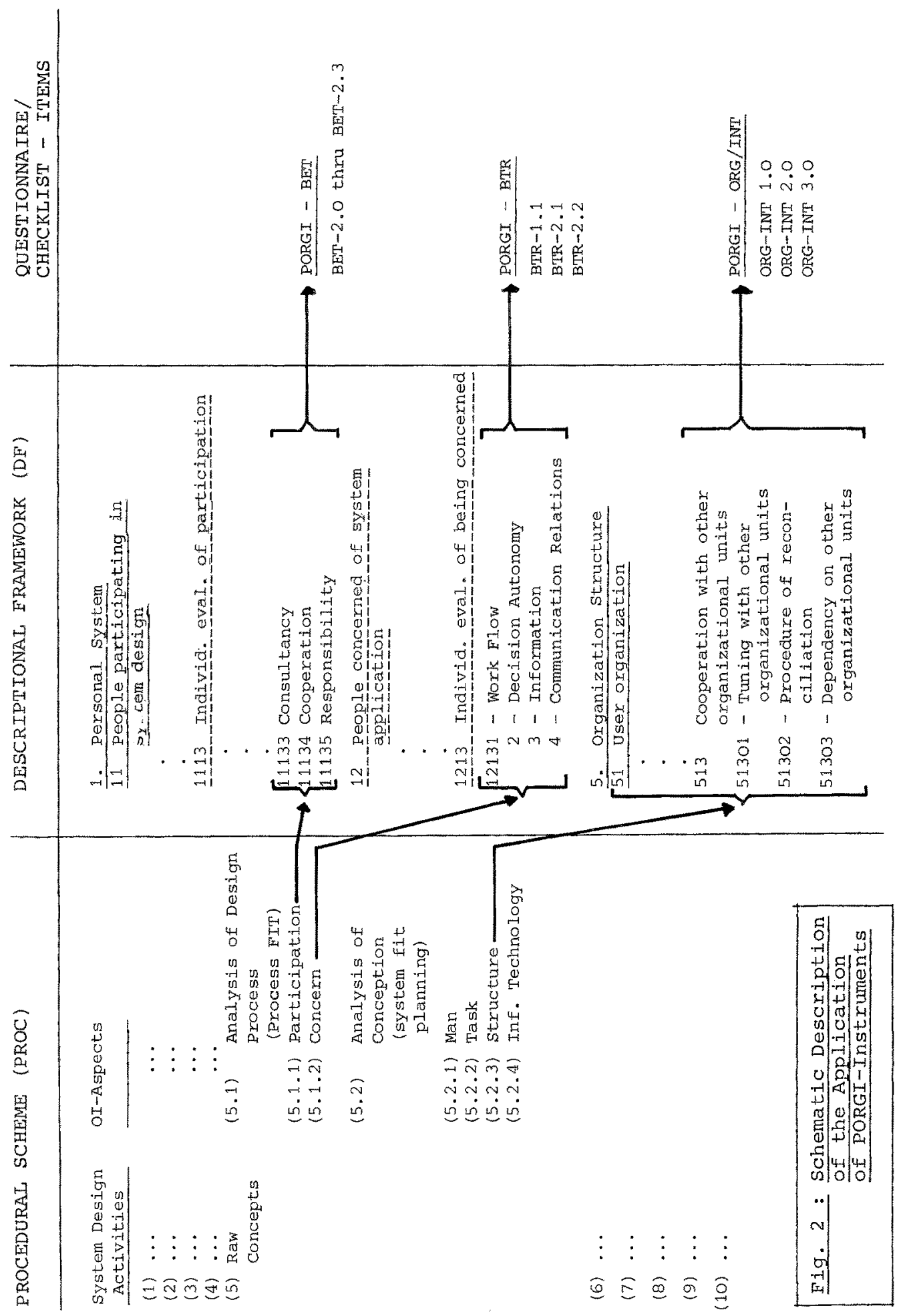


9. Implications and limitations of the PORGI-approach

- The approach is focused on the integration of technological, organizational and human system components as one of the main tasks of CBIS-development. The authors think that the performance of this task is crucial to system success. Knowledge about how to achieve this integration up to now is of a fragementary nature. PORGI tries to coordinate and organize the existing knowhow, to enriche it with additional tools and bridge the existing gap between research and system development, which has hindered the perception of valuable empirical findings by practitioners.

The main advantage of the required O.I.-activities will be that the risk of unseccessful systems and unsuccessful system development decreases. On the other side it must be clear that O.I.-activities cause additional expenses. It starts with the training of highly qualified system people, which are able and willing to take the role of "implementors", people, which will become responsible for the implementation activities shown in chapter 4. This may require additional manpower compared to the traditional procedures of system development.

In some cases there will be a personal union of the project management function and the O.I.-function, in other cases (e.g. large projects) there might be a division of labour between project managers and specialized implementators. In some cases (e.g. smaller projects) the O.I.-function might be performed by external consultants.

Some technologically oriented system designers apply a special conception or strategy, which might be called "release of bombs"strategy. It can be characterized as follows: In their view personal and social behavior of future users and system specialists is so complex and multidimensional that it cannot be measured and controlled. They feel that the utility of extending the area of measured and controlled variables is lower than the cost of research necessary to achieve such an increase of know-how plus the cost of know-how-introduction and -application.

Therefore they concentrate on the efficient production of technological system components, leave organizational implementation to the future user and hope that the user will succed in understanding and adapting the new system to his individual situation. As the user sometimes is not prepared to face and to solve such 
problems the delivery of new systems might have the same effects as the "release of bombs". Nevertheless the adherents of this strategy don't see efficient ways to avoid these effects.

- We think that we cannot restrain anybody of applying such a strategy, but maybe using O.I.-methods like those developed in project PORGI could lower the risk of such releases.

- Another objection against this approach could concentrate on the fact, that transparency of system development processes is rigorously increased. It might be that this is not in accordance with the management style of some organizations. If management style cannot be changed to accept more transparency we would not recommend to make a practice on this approach. On the other side: Most system development processes are already understood as "bargaining processes". Applying tools like those proposed here will lead to rationalization of these processes.

- The PORGI-approach is focused on the development of single "local" (sub-) systems. Long-range and global system planning problems (like definition of priorities of competing projects) are not discussed here. This does not mean, that such a participative approach would not be applicable to long-term global systems planning. It only means that you need specialized tools to support such planning processes.

- The traditional "classical" activities of system design concentrate on the question: which technological alternative is the best (most efficient) one to solve a given, predefined task? Concentration of PORGI-tools on planning and control of the fit between technological and organizational/human system components supposes that this question has been or will be answered during system development. The PORGI-approach does not support answers to this difficult and in many cases very unclear guestion (for which a large amount of research always will be needed). But this limitation has been chosen deliberately. The PORGI-approach does not intend to substitute existing system design approaches, which concentrate on the questions of optimizing technological solutions for predefined tasks, but complement them in respect to certain factors extremely relevant to system success.

- Chapter 1 of this paper has related O.I.-problems to computexbased management information systems. Today it has become clear, that M.I.S. were among the first examples, where such problems 
were encountered, but management orientation is neither the only nor the main reason for producing $O . I$.-problems within system development. We find such problems within those classes of system development, where we try to support relatively weekly structured but complex information processing tasks with CBIS and where the users of CBIS are not able (for different reasons) to create these CBIS themselves. In many organizations relatively simple and highly structured tasks have already reached a high degree of computer support. Therefore we feel that systems with O.I.problems will dominate the future of system designers and implementors.

Organizational Implementation of CBIS has many different - last not least cognitive and political - dimensions. The tools proposed here do not cover all these dimensions and the problems stemming from them. The PORGI-approach directs attention to some of these problems and tries to find methods better adjusted to the complexity of reality. Continous improvement of these methods during a longer period (much longer than the duration of project PORGI) is necessary. Applications of the tools within organizations should be structured as systematic learning processes. 
10.

References

Bean, A.S.; Neal, R.D.; Radnor, M.; Tansik, D.A. = Correlates = Structural and Behavioral Correlates of Implementation in U.S. Business Organizations. In: Schultz/slevin = Implementierung $=$, $S$. 77-132

Carter, Deane, M.; Gibson, Harry I.; Rademacher, Robert A. = Factors = zum Situationsansatz in der organisationsforschung. In: $\mathrm{zfO}, 46 . \mathrm{Jg} .(1977), \mathrm{Nr} .2, \mathrm{~S} .67-74$

Chervany, N.L.; Dickson, G.W. = Informations Overload = An Experimental Evaluation of Information Overload in a Production Environment. In: Management Science, Vol. 20, 1974 , S. 1335-1344

Dyckmann, T.T. = Attitudinal Study = Management Implementation of Scientific Research: An Attitudinal Study. In: Management Science, Vol. 13, 1967, No. $10, \mathrm{~B} 612-\mathrm{B} 620$

Ginzberg, M.J. = Implementation =

A Detailed Look at Implenentation Research. Report CISR-4, Sloan School of Management, MIT, Working Paper 753-4, November 1974

Harvey, Allan = Factors $=$ Factors making for Implementation Success and Failure.

In: Management Science, Vol. 16, 1970, No. 6, S. B312-B321

Hawgood, J. = Evaluation =

Evaluation and management of computer-based systems: an inter-disciplinary approach. Information Processing 71. Ansterdam 1972

Hawgood, J.; Land, E.F.; Mumford, E. = Comparison = Comparison of alternative strategies and systems.

In: Datenverarbeitung im Europäischen Raum. Wien 1972, S. 283-287

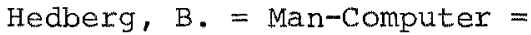
On Man-Computer Interaction in Organizational DecisionMaking. A Behavioral Approach. Gothenburg 1970

Huysmann, J.H.B.M. = Joint Consideration = The Implementation of Operations Research: An Approach to the Joint Consideration of Social and Technological Aspects. New York, 1970

Ladd, D.E. = Group's Reaction = Report on a Group's Reaction to the "Researcher and the Manager": A Dialectic of Implementation. In: Management Science, Vol. 12, 1965, No. 2, B24-B25

Leavitt, H.F. = Change = Applied Organizational Change in Industry. Structural, Technological, and Humanstic Approaches. In: March, J.G. (Ed.): Handbook of organizations. Skokil, Ill., 1965, S. 1144-1170

Little, J.D.C. = Models = Models and Managers: The Concept of a Decision Calculus. In: Management Science, Vo1. 16 (1970), No. 8, S. B466-B483

Lucas, H.C. = Performance $=$

Performance and the Use of an Information System.

In: Management Science, Vol. 21, No. 8, 1975, S. B908-B912

Lucas, Henry C. = Systems = Why Information Systems Fail. New York, London 1975

Mumford, Enid = Procedures $=$ Procedures for the Institution of Change in work Organization. Participative work design: A contribution to democracy in the office and on the shop floor. Unpublished Paper. Manchester Business School, 1976 
Mumford, Enid = Job Satisfaction = Job Satisfaction. A Study of Computer specialists. London 1972

Powers, Richard F.; Dickson, Gary $W$. = MIS = MIS Project Management: Myths, Opinions and Reality. In:

California Management Review, Vol. 15, 1973, No. 3, S. 147-156

Radnor, M.; Rubenstein, A.H.; Bean, A.S. = Integration = Integration and Ultilization of Management Science Activities in Organizations. In: Operations Research Quarterly, Vol. 19, 1968 , No. 2, S. 117-141

Radnor, M.; Rubenstein, A.H.; Tansik, D.A. = Implementation = Implementation in Operations Research and $R$ \& $D$ in Government and Business organizations. In: Operations Research, Vol. 18, 1970, S. $967-991$

Schultz, R.L.; Slevin, D.P. = Organizational Validity = Implementation and Organizational Validity: An Empirical Investigation. In: Schultz/Slevin = Implementing =, S. $153-182$

Shaw, Marvin E. = Group Dynamics = Group Dynamics: The Psychology of Small Group Behavior. New York 1971

Sorensen, R.E.; Zand, D.E. = Improving = Improving the Implementation of OR/MS Models by Applying the Lewin-Schein Theory of Change. In: Schultz/Slevin $=$ Implementing $=, \mathrm{S} .217-236$

Whisler, T.L. = Impact of Computers = The Impact of Computers on Management. 1970 
11. Appendix : Parts of PORGI-Tools

A. Situational Diagnosis : BET-2.0 thru BET-2.2

B. Situational Diagnosis : BTR-1.1

C. METH : ORG-INT-1.0 thru 3.0

D. Checklist Problem Definition And Analysis : PROB-1.0 and 3.0 
2.0 Conceptual Design of the System

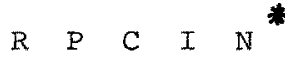

2.1 What kind of participation have you experienced?

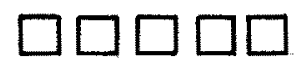

2.2 What kind of participation would have been appropriate ?

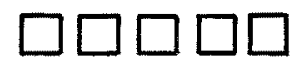

2.3 If you would like to participate more intensive, what reasons do you see ?

(1) The consideration of my know-how/knowledge would be helpful

(2) The consideration of my requirements is justified and necessary

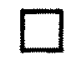

(3) To avoid disadvantages for my own position my participation is necessary

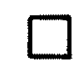


2.4 If you would like to participate less intensive, what reasons do you see?

(1) The consideration of my know-how/ knowledge is not necessary

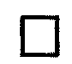

(2) I don't have requirements to that specific system to be considered

(3) I don't have the time available

(4) Other :

2.5 If you would like to have participated in a different way (more or less intensive), have you tried to accomplish it ?

2.6 If you would like to have participated in a different way but not tried to accomplish it, what reasons were responsible?

(1) I didn't get any information about that project

(2) I don't have available

a. the required time

b. the required know-how

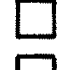

(3) I don't have good experiences by active participating or starting initiatives for it

(4) Would look like criticism for my superiors

(5) Wish to participate less intensive would look like an admission of incompetence or lack of interest 
(6) Wish to participate more intensive would look like "lust for power or promotion"

(7) Other :

2.7 If you have tried to accomplish a different kind of participation but you didn't succeed, what were the reasons?

(1) I don't know the reasons

(2) The consideration of my know-how/ experiences ...

a. is not necessary

b. would be helpful but not realizable with available time 
1.1 For which of the below mentioned task-oriented aspects do you expect or know changes induced by the system design and what importance do they have for you?

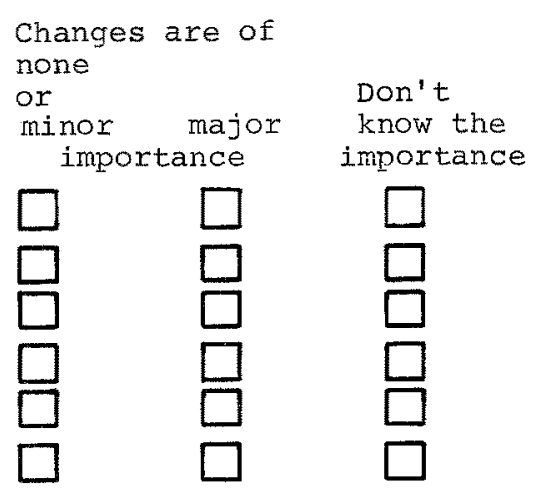
a. task assignment
b. work flow
c. decision autonomy
d. responsibility
e. information
f. quality of own work
g. Other :

1.2 For which of the below mentioned person-oriented aspects do you expect or know changes induced by the system design and what importance do they have for you ?

Changes are of none

$$
\text { or }
$$
minor major importance Don't know the importance
a. personal image
b. influence
c. chances for promotion
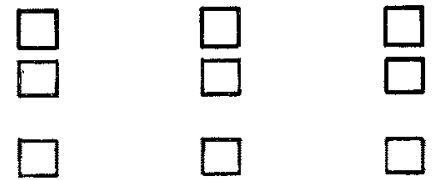

d. financial implications

e. personal well-being

f. work load/stress
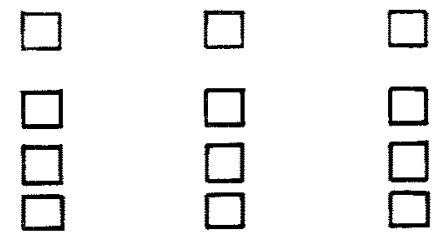

g. Other : 
1. What is the official hierarchial structure of that department/division etc. ?

(if possible take plan of organization)

2. Which meetings, conferences etc. exist in your department ?

2.1 Name : (1)

(2)

(3)

2.2 How often do they take place?

No. Erequency

(1)

(2)

(3)

2.3 Who takes part ?

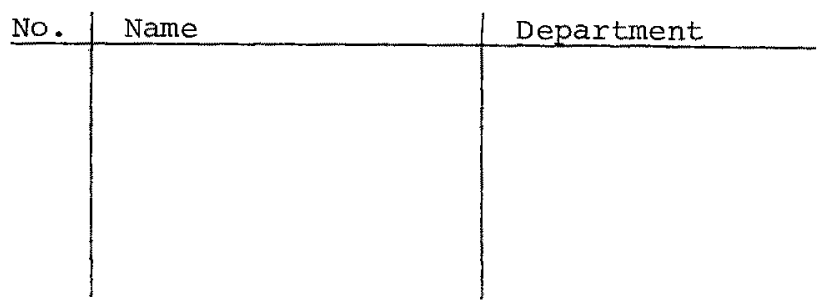

2.4 What is the subject of these meetings?

No. $\mid$ Subject area 
2.5 Of which character are these meetings?

- Exchange of information ............ No.

- Discussion of proposals ............ No.

- Elaborating of problem solutions ....... No.

- Common decision-making .............. No.

2.6 Are you content with the realization of these meetings ?

$\square$ Yes

No, because

$\square$ too seldom

too often

$\square$ wrong persons

$\square$ irrelevant/peripher problems

$\square$ without obligation

Other :

3. Regarding the planning task to be supported by the new system who in your department

3.1 is intensively occupied with operative activities ?

3.2 represents proposals against other departments ? 
4. Is the preparation of a plan proposal being performed

$\square$ solely in your department

$\square$ mainly in your department and

other departments

$\square$ delivers specified inputs

$\square$ will be informed about the proposal

$\square$ mainly in other departments and your department

$\square$ delivers specified inputs

$\square$ will be informed about the proposal

5. Are you involved in the

5.1 preparation of plan proposals ?<smiles>C1CCC1</smiles>

5.2 discussion of plan proposals ?

$\square$ Yes $\quad \square$ No

5.3 ratification of plan proposals ?

$\square$ yes $\square$ No 
The following checkpoints have to be considered in problem definition and analysis :

1. Charactexistics of the problem situation

1.1 Characteristics of task performance (See PROB-3.0, 3.1)

1.2 Characteristics of the technological support of task performance

(See PROB-5.0)

1.3 Characteristics of the personal system (See PROB-4.0)

1.4 Characteristics of the organizational structure

(see PROB-6.0, 6.1)

2. Members or organizational units,

2.1 who/which are concerned by that problem

- task assignment

- work flow

- decision autonomy

- responsibility

- information

(See Checklist BTR and analytical scheme)

2.2 who/which have articulated that problem

2.3 who/which initiated the study

(See Role structure in PROB-6.0)

PORGI 


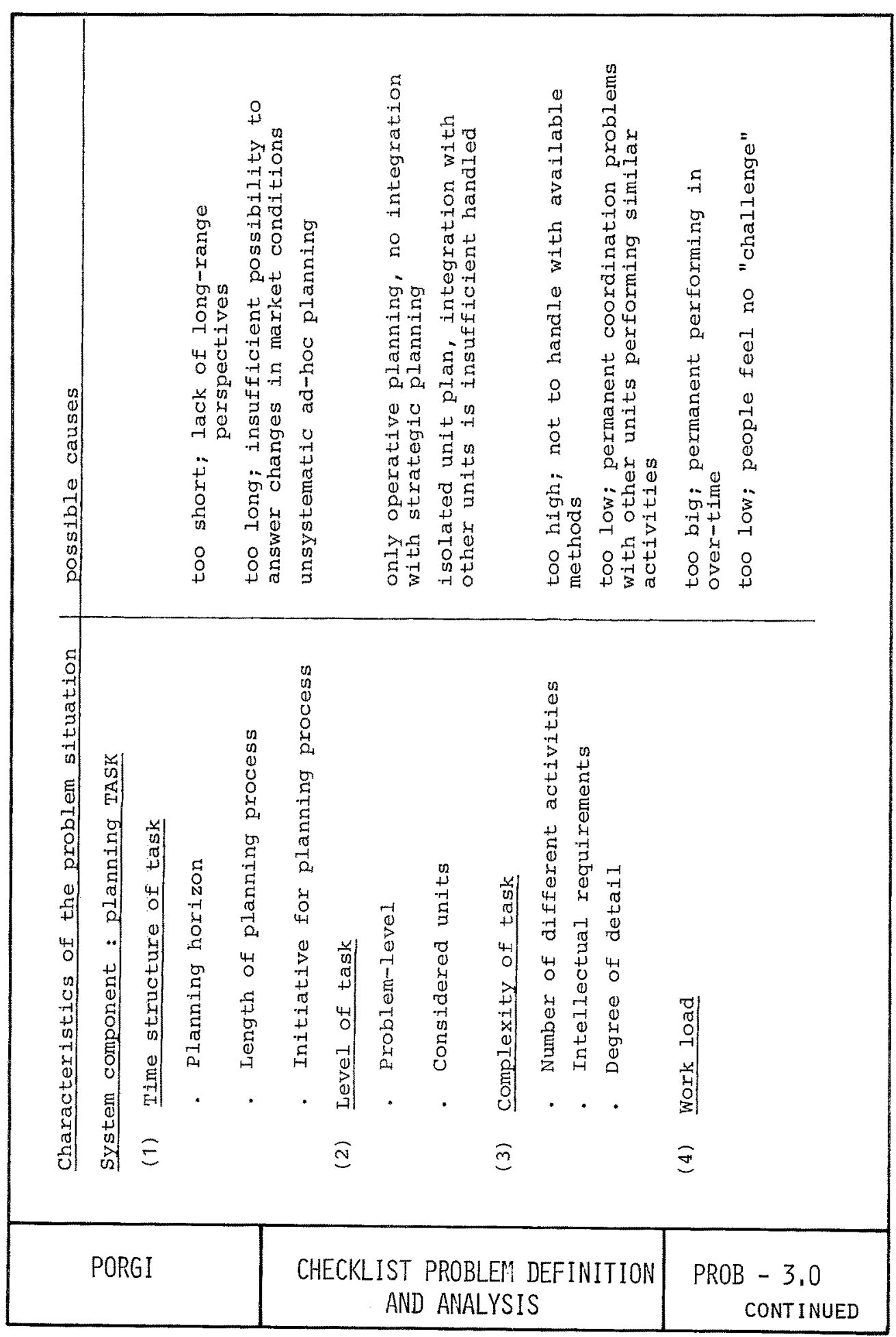

